\title{
Postnatal inactivation of Shank3 expression is insufficient to produce behavioral phenotypes associated with germline deficiency
}

Samuel William Hulbert

Duke University https://orcid.org/0000-0003-0369-0150

Haidun Yan

Duke University

Xiaoming Wang

Duke University

Alexandra L. Bey

Duke University

Mary S. Lin

Duke University

Yong-hui Jiang ( $\nabla$ yong-hui.jiang@yale.edu )

Yale University School of Medicine

Research

Keywords: behavior, electrophysiology, Shank3, mouse models, ASD, development

Posted Date: June 1st, 2020

DOI: https://doi.org/10.21203/rs.3.rs-31397/v1

License: (1) This work is licensed under a Creative Commons Attribution 4.0 International License.

Read Full License 


\section{Abstract}

Background: The developmental origins of Autism Spectrum Disorder (ASD) remain largely unknown. To begin to answer this question, a few studies have implemented conditional gene expression technology to induce or rescue ASD-causing mutations at different times during mouse development.

Methods: In the current study, we crossed a ubiquitously-expressed inducible Cre line with mice containing loxP sites surrounding Shank3 exons 4-22 (Shank3 e4-22 flox). We then delivered tamoxifen to determine the effects of disrupting Shank3 expression during two different time periods in development.

Results: We found that reducing Shank3 expression in fully developed mice had minimal effects on behaviors that are characteristic of the conventional knockout mice. Similarly, disrupting Shank3 expression during an earlier time period (postnatal day 10-21) did not induce behaviors associated with germline deficiency. However, we observed differences in electrophysiological phenotypes for the two groups of conditional knockout mice.

Conclusions: Because inducing mutations in adult mice or during early postnatal development is insufficient to cause ASD-like behaviors, Shank3 may play a role even earlier in development, but limited efficiency of the disruption could have contributed to our negative results. We also report considerable mortality when delivering tamoxifen across several different routes of administration, bringing further attention to caution the use of this type of conditional gene expression technology in future studies.

\section{Background}

It has been proposed that Autism Spectrum Disorder (ASD) results from disruptions to synaptic development during a critical period of brain plasticity. Patients are typically diagnosed within the first three years of life, corresponding to a period of rapid growth and refinement of neural connections. However, much remains to be discovered regarding the developmental pathogenesis of the disorder. The Shank3 mouse model of ASD is well-suited to determine whether disruptions to synaptic development contribute to ASD pathogenesis because in vitro studies have directly linked Shank3 to the formation of synapses (Roussignol et al., 2005) and in vivo studies utilizing conventional knockouts have presented synaptic deficits along with multiple ASD-like and comorbid behavioral phenotypes (Bozdagi et al., 2010; Peça et al., 2011; Wang et al., 2011; Duffney et al., 2013; Kouser et al., 2013; Drapeau et al., 2014; Duffney et al., 2015; Lee et al., 2015; Speed et al., 2015; Jaramillo et al., 2016; Wang et al., 2016; Zhou et al., 2016; Jaramillo et al., 2017; Drapeau et al., 2018; Hulbert et al., 2018).

Conditional knockout technology has been developed for use in mice to manipulate gene expression over space and time. This technology has allowed researchers to identify brain regions and cell types involved in the manifestation of ASD-like behaviors in mouse models (Bey et al., 2018). It has also allowed for researchers to begin to study the developmental trajectory of the disorder and the reversibility of behavioral phenotypes through genetic rescue (reviewed in (Hulbert and Jiang, 2017)). Although it has been demonstrated that a subset of phenotypes can be rescued in adulthood through restoring Shank3 
expression (Mei et al., 2016), it has not yet been determined whether ASD-like behaviors can be induced by disrupting Shank3 expression in fully developed organisms, or whether there is a critical period in development for Shank3 expression. In some mouse models of ASD, such as with Mecp2 mutants, it appears that some phenotypes can be induced in adult mice through conditional knockout and reversed in adult mutants by genetic rescue (Guy et al., 2007; McGraw et al., 2011; Robinson et al., 2012; Lang et al., 2014). However, in other models, such as with Ube3a mutants, certain phenotypes cannot be reversed in adult mutants by genetic rescue or induced through postnatal deletion (Silva-Santos et al., 2015; Sonzogni et al., 2019). This suggests that different ASD-causing mutations may have varying consequences during development.

In the current study, we crossed a ubiquitously-expressed inducible Cre line, $\mathrm{Tg}$ (CAG-cre/Esr1*)5Amc (CAGGS-CreER; JAX 004453) with mice containing loxP sites surrounding Shank3 exons 4-22 (Shank3

e4-22 flox $)$. We then delivered tamoxifen to determine the effects of disrupting Shank3 expression during two different time periods in development. We found that reducing Shank3 expression in fully developed mice had minimal effects on behaviors that are characteristic of the conventional knockout mice. Similarly, disrupting Shank3 expression during an earlier time period (postnatal day 10-21) did not induce behaviors associated with germline deficiency. This suggests that Shank3 may play a role in development prior to synaptogenesis. However, limited efficiency of the disruption could have contributed to our negative results. For both groups of mice, we used conventional germline knockout littermates to act as positive controls and found that the behavioral phenotypes for these mice were fairly consistent with what was previously observed.

\section{Methods}

\section{Animals}

Shank3 e4-22 flox and e4-22-/- mice previously generated and characterized by the Jiang lab were maintained on a C57BL/6J background after backcrossing for at least 8 generations (Wang et al., 2016). We crossed the Shank3 e4-22 flox and e4-22/- mice with the ubiquitously-expressed inducible Cre line, $\mathrm{Tg}$ (CAG-cre/Esr1*)5Amc (CAGGS-CreER) [Stock No. 004453, Jackson Laboratories, Bar Harbor, ME], which we also backcrossed to a C57BL/6J background for at least 8 generations. This allowed us to create two groups of inducible knockout mice: one group with both Shank3 alleles floxed $(\mathrm{fl} / \mathrm{fl})$ and one group with one Shank3 allele floxed and one null Shank3 allele (fl/-). Our breeding scheme (female Shank3 e4-22 flox/- mice and male CAGGS-CreER+; Shank3 e4-22 flox/-mice) allowed us to generate germline knockout mice (-/-) as littermates and positive controls, as well as both groups of inducible knockout mice. For both adult knockout (AKO) and early postnatal knockout (EPKO) groups and for both types of inducible knockouts (fl/fl and fl/-) "control" groups were a combination of mice who either did not express the Cre transgene, did not receive tamoxifen, or both. The mice designated as AKO or EPKO were $\mathrm{Cre}+$ and were given tamoxifen during the corresponding developmental period. We observed some "leakiness" of the Cre (i.e. some recombination in offspring without tamoxifen administration) during 
pilot experiments using Cre+ females as breeders, so we only used Cre+ males as breeders for all experiments presented in this paper. All experiments were conducted with protocols approved by the Institutional Animal Care and Use Committee at Duke University.

\section{Tamoxifen administration}

We first sought to develop a paradigm in which to deplete Shank3 expression in adult and developing mice. We attempted to deliver tamoxifen dissolved in corn oil through both intraperitoneal injections, subcutaneous injections, and through oral gavage, which have all been previously reported in the literature. In all cases, we observed a high rate of mortality in the mice, regardless of genotype. We then switched to using a tamoxifen containing diet (Envigo Teklad $250 \mathrm{mg} / \mathrm{kg}$ diet, red color, Stock No. TD.130856), which allowed us to minimize toxicity and simultaneously reduce handling stress, which is particularly important for behavioral experiments.

For the AKO condition, we put the mice on the tamoxifen-containing diet for four weeks starting on postnatal day 60 (P60), allowed them to recover on a normal diet for two weeks, and then placed them on the tamoxifen-containing diet for an additional four weeks, culminating in 8 weeks total of exposure to the tamoxifen-containing diet. This reduced mortality to approximately $25 \%$ and maximized efficiency of eliminating the Shank3 protein. During a pilot experiment, we placed some mice on the tamoxifencontaining diet for a total of 16 weeks and this did not increase the efficiency compared to the 8 week condition. For the early postnatal knockout condition, we put nursing mothers (breeders, who were Cre negative) on the tamoxifen-containing diet and tamoxifen was delivered via the lactating dam to pups from postnatal day 10 (P10) to postnatal day 21 (P21). This resulted in similar mortality rates and Shank3 deletion efficiency to the adult knockout condition.

\section{Isolation of striatal postsynaptic density fractions}

Isolation of crude postsynaptic densities (PSDs) was performed as previously described (Wang et al. 2016) to determine the deletion efficiency of our conditional knockout models. Protease and phosphatase inhibitors were used throughout at a concentration of 1:200 each and the entire process was done at $4^{\circ} \mathrm{C}$. Striata from mice in each of the 10 groups (fl/fl control, $\mathrm{fl} / \mathrm{fl}$ conditional knockout, $\mathrm{fl} /$ - control, $\mathrm{fl} /-$ conditional knockout, -/- for each developmental time point) were homogenized in HEPES-buffered sucrose (0.32 M sucrose, $4 \mathrm{mM}$ HEPES, pH 7.4) and centrifuged at $800 \times \mathrm{g}$ for $10 \mathrm{~min}$. The supernatants were transferred to a new set of tubes and centrifuged at 12,000 $\times \mathrm{g}$ for $15 \mathrm{~min}$. The supernatant from this step was discarded. The pellet was lysed using water, then buffered with HEPES (pH 7.4) to $4 \mathrm{mM}$, and the sample was mixed by rotation for $30 \mathrm{~min}$, followed by centrifugation at $20,500 \times \mathrm{g}$ for $30 \mathrm{~min}$ to yield the synaptosomal membrane (SPM) fraction. The SPM was resuspended in a buffer containing 50 mM HEPES (pH 7.4), 2 mM EDTA, and 0.5\% Triton-X 100. After 15 min of mixing by rotation, the crude PSD fraction was obtained by centrifugation at $32,000 \times \mathrm{g}$ for $20 \mathrm{~min}$. The crude PSD pellet was dissolved in $1 \%$ SDS in PBS for further immunoblot analysis. 


\section{Quantitative immunoblot analysis}

An equal amount of total protein from each striatal PSD fraction was loaded and separated by SDSPAGE. Proteins were transferred to PVDF membranes (Bio-Rac, Hercules, CA). The membranes were then blocked for $1 \mathrm{hr}$ in $5 \%$ non-fat milk in TRIS-buffered saline (TBS, pH 7.4). Then they were incubated with the primary antibodies diluted in the same solution overnight at $4^{\circ} \mathrm{C}$. The following day, the membranes were washed in TBS containing $0.1 \%$ Tween-20 (TBST) and then were incubated with HRP-conjugated secondary antibodies diluted in $5 \%$ non-fat milk in TBS for $1 \mathrm{hr}$ at room temperature. Following 3 additional washes in TBST, the membranes were incubated with ECL reagent (Thermo Fisher Scientific, Waltham, MA) and then imaged on a ChemiDoc MP Imaging System (Bio-Rad). The gray values of Shank3 protein were measured using Image J software $(\mathrm{NIH}$, Bethesda, MD) and normalized to a corresponding internal control ( $\beta$-tubulin III).

\section{Antibodies}

The Shank3 antibody was a generous gift from YongQing Zhang from the Institute of Genetics and Development at Chinese Academy of Science and was used at a 1:5,000 dilution. The $\beta$-tubulin III antibody (ab18207) was purchased from Abcam (Cambridge, MA) and was used at a 1:10,000 dilution. The HRP-conjugated secondary antibodies were purchased from Santa Cruz Biotechnology and were used at the same dilution as their respective primary antibodies.

\section{Behavioral phenotyping}

\section{Cohorts for behavioral assays}

Three cohorts containing mice from the five groups (fl/fl control, fl/fl conditional knockout, fl/- control, fl/conditional knockout, -/-) in each of the AKO and EPKO conditions were run through a battery of behavioral tests, for a total of 6 behavioral cohorts for this study. The experimenter was blind to both genotype and rearing conditions until data analysis. The assays were performed in order they are described for all cohorts. Both male and female mice were used for all experiments presented in this 
study, except for ultrasonic vocalizations, which is largely a sex-specific behavior.

Open field locomotion

Activity in the open field was measured for 1 hour in an automated Omnitech Digiscan apparatus (AccuScan Instruments, Columbus, $\mathrm{OH}$ ). AccuScan software calculated the total distance traveled and time spent in the center of the arena.

Self-grooming

Individual animals were placed into clean home cages without bedding and acclimated for five minutes. Mice were filmed for $\mathbf{1 0}$ minutes and then videos were later manually scored for time spent grooming.

Rotarod

Performance on the rotarod (Med-Associates) was assessed over four trials lasting five minutes each. The inter-trial interval was $\mathbf{3 0}$ minutes. The rod started at four rotations per minute (RPM) and slowly increased to 40 RPM over the five-minute trial.

Operant conditioning

Mice were food restricted until they reached approximately $85 \%$ of their original body weight. Individual operant conditioning chambers (Med-Associates) were equipped 
with a retractable lever and a liquid dipper that delivered a drop of sweetened condensed milk as a food reward. The Med-PC-IV program was used to create the reinforcement schedule and record the data. The paradigm consisted of seven days of continuous reinforcement (one lever press earned one drop of sweetened condensed milk every time). Each session began with illumination of the chamber and presentation of the lever and ended with extinguishing the light and retracting the lever. Trials ended after either one of two conditions had been satisfied: 60 minutes had passed or the mouse had pressed the lever 100 times.

Ultrasonic vocalizations

Male mice were given breeding experience with an agematched female mouse for at least four days (the duration of the estrous cycle) and then were individually housed for at least $\mathbf{2 4}$ hours. For testing, the male mice were placed in a sound-attenuating styrofoam chamber equipped with an externally polarized condenser CM16/CMPA microphone with a frequency range of $10-200 \mathrm{kHz}$ (Avisoft Bioacoustics Inc.) suspended $20 \mathrm{~cm}$ above the floor of the chamber. After the test mouse acclimated for 10 minutes, an 8-10 week old virgin female C57BL/6J mouse (Jackson Labs) was added to the chamber and vocalizations were recorded for five minutes as waveform audio files using Avisoft-RECORDER. The files were analyzed later using Avisoft SASLab Pro software. Mice that did not call were excluded from analysis.

Electrophysiology 
Coronal slices of the striatum $(300 \mu \mathrm{m})$ were obtained from mice following treatment with tamoxifen using a vibratome series 1000 sectioning system (Vibratome, St. Louis, MO) after isoflurane anesthesia and decapitation. The slices were cut with ice-cold high sucrose cutting solution containing the following (in mM): 220 sucrose, $3 \mathrm{KCl}, 1.25 \mathrm{NaH}_{2} \mathrm{PO}_{4}, 25 \mathrm{NaHCO}_{3}, 12 \mathrm{MgSO}_{4} \cdot 7 \mathrm{H}_{2} \mathrm{O}, 10 \mathrm{Glucose}$, and $0.5 \mathrm{CaCl}_{2}$, bubbled with $95 \% \mathrm{O}_{2}$ and $5 \% \mathrm{CO}_{2}$. The slices were immediately moved into modified artificial cerebrospinal fluid (ACSF) containing (in mM): $120 \mathrm{NaCl}, 3.3 \mathrm{KCl}, 1.23 \mathrm{NaH}_{2} \mathrm{PO}_{4}, 1 \mathrm{MgSO}_{4}, 2 \mathrm{CaCl}_{2}, 25$ $\mathrm{NaHCO}_{3}$, and 10 glucose with $\mathrm{pH} 7.3$, previously saturated with $95 \% \mathrm{O}_{2}$ and $5 \% \mathrm{CO}_{2}$. The brain slices were allowed to equilibrate for $40-60 \mathrm{~min}$ at $33^{\circ} \mathrm{C}$ in ACSF solution that continuously bubbled with a mixture of $95 \% \mathrm{O}_{2}$ and $5 \% \mathrm{CO}_{2}$ gas. Slices were then kept in bubbled ACSF with at room temperature $\left(22-24^{\circ} \mathrm{C}\right)$ until recordings were initiated.

The slices were perfused by bubbled ACSF at $29-30^{\circ} \mathrm{C}$ with a $2 \mathrm{~mL} / \mathrm{min}$ flow rate. The slice was visualized with infrared differential interference contrast (DIC, Zeiss Axio Examiner D1), using an upright microscope, with a $\times 40$ water-immersion objective, and displayed on a monitor. Recording of action potentials were performed from medium spiny neurons (MSNs) in the dorsolateral striatum. Recordings were made by whole cell patch recording techniques using the Multiclamp 700B amplifier (Molecular Devices, Axon Instruments Inc., Union City, CA). The signals were filtered at $10 \mathrm{kHz}$ and acquired using Digidata 1440A and pClamp 10.7 (Axon Instruments, Molecular Devices). Patch pipettes were borosilicate glass capillaries (1.5 mm OD, $1.1 \mathrm{~mm} I D$, Sutter Instrument, Novato, CA), pulled on a Flaming/Brown Micropipette Puller (Sutter Instrument, Model P-87) to produce electrodes with 3-4 M $\mathrm{M}$ resistance. The pipette solution for current-clamp experiments consisted of (in $\mathrm{mM}$ ) $130 \mathrm{~K}$-gluconate, $5 \mathrm{KCl}, 2 \mathrm{MgCl}_{2}, 0.2$ EGTA, 10 HEPES, 4 Mg-ATP, $0.5 \mathrm{Na}$-GTP, and 10 phosphocreatine, pH adjusted to 7.3 with $\mathrm{KOH}$ (290 mosM). The access resistance was monitored throughout each experiment, and only recordings with stable access and holding current for at least 3 min were used. Data were excluded from analysis when the series resistance changed by $>15 \%$. The liquid junction potential was estimated to be $15.9 \mathrm{mV}$ for the normal ACSF solution and was not corrected. Input resistance was calculated from membrane voltage deflection, evoked by 600 -ms hyperpolarizing current injections ( 0 to -300 pA in steps of $50 \mathrm{pA})$ and calculated from the measured slope. Changes in neuronal excitability were assessed by determining rheobase, single action potentials were elicited by 10 ms depolarizing current injections with $10 \mathrm{pA}$ increments in current-clamp mode. Single action potential amplitude was calculated as a difference between the threshold and positive peak. Action potential frequency was determined by quantifying the number of action potentials elicited in response to series of depolarizing current injections from $0 \mathrm{pA}$ to 400 pA for 600 ms duration with 10 pA increments.

\section{Results}

\section{Shank3 expression can be depleted in adult mice with limited efficiency}


First, we wanted to see whether there was any role of neurodevelopment in the manifestation of ASD-like behaviors of Shank3 deficient mice. We therefore optimized a system to deplete Shank3 expression in fully developed mice and assessed their behavior to test whether Shank3 mutations that are induced in adult mice can produce phenotypes that are consistent with germline deletion. Our previous analysis indicated that Shank3 expression levels in Shank3 e4-22 flox/flox mice is equivalent to wildtype mice (Bey et al., 2018). Similarly, CAGGS-CreER; Shank3 e4-22 flox/flox mice develop with wildtype levels of Shank3. Delivering tamoxifen to CAGGS-CreER; Shank3 e4-22 flox/flox mice allows for recombination of the floxed DNA sequences. After putting the CAGGS-CreER; Shank3 e4-22 flox/flox (fl/fl AKO) mice on a tamoxifencontaining diet for eight weeks, only a modest reduction of Shank3 protein was observed in the postsynaptic density (PSD) fractions of the striatum, in which the highest expression of Shank3 is observed (Wang et al., 2014), compared to controls (Figure 1A).. We therefore took advantage of the fact that the heterozygous Shank3 $\Delta \mathrm{e} 4-22^{+/-}$mice show little to no phenotype (Hulbert et al. 2018, Wang et al. 2016) to induce a deletion of the remaining allele in Shank3 e4-22 flox/- mice. After eight weeks on a tamoxifen-containing diet, CAGS-CreER; Shank3 e4-22 flox/- (fl/- AKO) mice showed a reduction in Shank3 protein approaching germline knockout levels, but this disruption was still not complete and variable (Figure 1B)..

\section{Adult knockout mice do not recapitulate behavioral phenotypes that have been observed in germline knockout mice}

Self-grooming is often elevated in mouse models of ASD and is thought to represent a repetitive behavior. Shank3 $\Delta \mathrm{e} 4-22^{-/-}$mice were previously reported to self-groom at significantly higher rates compared to wildtype and heterozygous mice (Wang et al., 2016; Bey et al., 2018; Drapeau et al., 2018; Hulbert et al., 2018). Our current study confirms this phenotype in the germline knockout mice, but there were no differences between $\mathrm{fl} / \mathrm{fl}$ AKO mice and their controls or fl/- AKO mice and their controls (Figure 2A)..

Ultrasonic vocalizations (USVs) are used to evaluate social communication in mouse models of ASD. Shank3 $\Delta \mathrm{e} 4-22^{-/-}$mice call fewer times and their calls are significantly shorter in length compared to wildtype and heterozygous mice (Wang et al., 2016). The cumulative duration of calls takes both measurements into account. There were no significant differences in cumulative duration of USVs between either AKO group and their controls (Figure 2B).. There was instead a trend for longer cumulative duration in both groups of AKO mice compared to their controls, which is the opposite direction of what is observed in the germline knockout mice (Figure 2B)..

The open field test is used to measure locomotor activity as well as anxiety-like behavior, as indicated by decreased time spent in the center of the arena. It was previously reported that Shank3 $\Delta \mathrm{e} 4-22^{-{ }^{-}}$mice are hypoactive and spend less time in the center of the chambers compared to wildtype and heterozygous mice (Wang et al., 2016). In the current study, disrupting Shank3 expression in adult mice 
had no significant effect on either activity (Figure 2C) or on time spent in the center of the open field apparatus (Figure 2D)..

Patients with ASD often have comorbid difficulties with motor coordination. The accelerating rotarod task is one way to measure motor coordination in mice. The Shank3 $\Delta \mathrm{e} 4-22^{-/-}$mice fall off the rotarod more quickly than wildtype or heterozygous mice (Wang et al., 2016). However, disrupting Shank3 expression in adult mice did not have any significant effect on rotarod performance (Figures $2 E-F$ )..

Intellectual disability also commonly presents with ASD. Operant conditioning is one way to assess learning and memory impairments in mice. A robust deficit on a reward learning task was previously reported in Shank3 $\Delta \mathrm{e} 4-22^{-/-}$mice (Wang et al., 2016). We replicated the protocol in the current study and found that disrupting Shank3 in adult mice does not impair performance on this task. In fact, the fl/fl AKO mice tended to perform better on this task compared to their control group (Figures 2G-H).. However, there were no significant differences between conditional mice and their control groups on this operant conditioning task (Figures 2G-H)..

\section{Disrupting Shank3 expression in adult mice can influence neuronal signaling properties}

We decided to use only the fl/- CTL and fl/- AKO groups for electrophysiological experiments because of the time-intensive nature of these experiments and because heterozygous Shank3 $\Delta \mathrm{e} 4-22^{+/-}$mice are not significant different from wildtype mice on electrophysiological measurements (Wang et al., 2016). We found that although there were no statistically significant differences in behavior between fl/- AKO mice and their controls, there were differences in the action potential dynamics of medium spiny neurons (MSNs) of the striatum (Figure $3 A$ ).. Recordings from these two groups of mice revealed no difference in the current threshold to produce action potentials (Figure 3B),, but action potential amplitude was increased in fl/- AKO mice (Figure $3 C$ ),, whereas action potential duration (Figure 3D),, rise time (Figure $3 E$ )and decay time (Figure 3F) were all decreased in fl/- AKO mice. Recordings from also revealed that MSNs from fl/- AKO mice were hypersensitive to current injection (Figure 3G) with increased action potential frequency at 325-500 pA (Figure 3F).. The observed differences were not due to differences in input resistance (Figure 3G)..

\section{Shank3 expression can be disrupted in developing mice with variable efficiency}

Overall, we observed that disrupting Shank3 expression in adult mice was insufficient to produce behavioral phenotypes associated with germline deficiency. This could indicate that Shank3 has a particular role in development that ultimately causes ASD-like behaviors to present in adulthood after this developmental process goes awry. To further explore this possibility, we then optimized the conditional 
knockout system to disrupt Shank3 expression earlier in development. We again used both CAGGS-Cre;

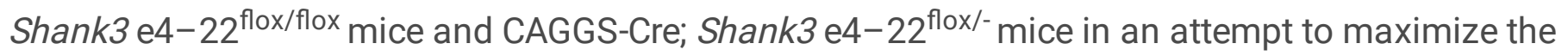
efficiency of the deletion. We found that that administering tamoxifen from P10-P21 had roughly equivalent efficacy to administering tamoxifen for 8 weeks during adulthood. After the CAGGS-CreER; Shank3 e4-22 flox/flox (fl/fl EPKO) mice received tamoxifen via the milk of their nursing mother, which was placed on a tamoxifen containing diet while the pups were P10-P21, many of these mice showed reduced Shank3 expression in the PSD of the striatum compared to their controls, resembling expression levels of germline heterozygous mice (Figure 4A).. Likewise, CAGGS-CreER; Shank3 e4-22 flox/- mice that were exposed to tamoxifen from P10-P21 showed a reduction in Shank3 expression compared to their control mice, often resembling expression levels of germline knockout mice (Figure $4 A$ ).. However, the Shank3 expression levels in these groups of mice were variable (Figure $4 B$ )..

\section{Disrupting Shank3 expression during an earlier period in development has minimal effects on behaviors associated with germline deficiency}

Like the AKO mice, the EPKO mice did not display significantly different rates of self-grooming compared to their controls (Figure 5A)..

Ultrasonic vocalizations were also not significantly altered in either of the EPKO groups (Figure 5B).. Notably, like AKO mice, EPKO mice tended to have longer cumulative durations of calls compared to their controls. However, these differences were once again not statistically significant.

In the open field, neither group of EPKO mice were hypoactive compared to their controls (Figure 5C).. In fact, each group tended to travel more distance in the open field than their controls, but these differences were not statistically significant. In terms of time spent in the center of the open field, neither group of EPKO mice performed significantly differently than their controls (Figure 5D)..

Motor coordination was also not affected following disruption of Shank3 expression during the early postnatal period. The EPKO mice did not perform significantly worse than their control groups on the accelerating rotarod task (Figure 5E).. In fact, fl/- EPKO mice performed statistically better than their controls (Figure 5F), the opposite of what is observed in germline deficiency.

Finally, like the adult knockouts, EPKO mice did not display impairments on the operant conditioning task (Figures 5G-H).. However, it is worth noting that all mice in the EPKO cohorts, including control mice, performed worse than what is typically observed on this task, for unknown reasons, making it difficult to detect differences between groups. 


\section{Early postnatal deletion of Shank3 has different effects on electrophysiology than adult deletion}

Like the adult knockout condition, early postnatal disruption of Shank3 expression impacted action potential dynamics in MSNs (Figure 6A).. However, whereas fl/- AKO mice showed no difference compared to their controls in the threshold current (Figure 3B),, fl/- EPKO mice required a significantly lower amount of current to produce an action potential compared to their controls (Figure 6B).. On the other hand, recordings from fl/- EPKO showed no changes in action potential amplitude (Figure 6C)," duration (Figure 6D), rise time (Figure 6E), or decay time (Figure 6F), whereas fl/- AKO mice were different from their controls on all these measurements. Like with the fl/- AKO mice, MSNs in fl/- EPKO were hypersensitive to current injection and produced more action potentials as a result (Figure $6 \mathrm{G}$ ),, but this occurred at a different range of current intensity: 200-350 pA (Figure 6H).. Unlike with fl/- AKO mice, this hypersensitivity could be attributed to increased input resistance in the fl/- EPKO neurons (Figure 6G)..

\section{Discussion}

We first wanted to determine whether disrupting Shank3 expression in fully developed mice could lead to the expression of behavioral phenotypes we have observed in Shank3 germline deficient mice. Our inability to induce these behavioral phenotypes in adult mice suggests that the behavioral phenotypes caused by Shank3 deficiency may be due to disrupted neurodevelopment, rather than ongoing neuronal dysfunction. Furthermore, our ability to produce some electrophysiological phenotypes in both AKO mice suggests that either these processes are unrelated to abnormal behavior or they may need to be disrupted during development to impact behavior.

Importantly, the relative inefficiency of the protein depletion limits our interpretation. This raises questions concerning what level of Shank3 suppression is sufficient to produce these phenotypes. In human patients, missing one copy of the SHANK3 gene is typically sufficient to produce a severe diagnosis of ASD (Durand et al., 2007; Moessner et al., 2007; Boccuto et al., 2013; Soorya et al., 2013), but across multiple studies in our laboratory and others, the majority of mice heterozygous for Shank3 have a mild or no phenotype with few exceptions (Bozdagi et al., 2010; Peça et al., 2011; Wang et al., 2011; Schmeisser et al., 2012; Kouser et al., 2013; Duffney et al., 2015; Lee et al., 2015; Speed et al., 2015; Jaramillo et al., 2016; Wang et al., 2016; Zhou et al., 2016; Jaramillo et al., 2017; Drapeau et al., 2018; Hulbert et al., 2018). This problem is common among genetic mutant ASD mouse models (Hulbert and Jiang, 2016). The evolutional difference between mice and humans could potentially explain why humans are more sensitive to smaller gene dosage changes. However, it should also be noted that isoform-specific Shank3 homozygous mutants do consistently display behavioral phenotypes, so it is unnecessary for all of the Shank3 protein to be depleted in mice to produce ASD-like behaviors when the mutation is made from germline (Bozdagi et al., 2010; Peça et al., 2011; Wang et al., 2011; Schmeisser et al., 2012; Kouser et al., 2013; Duffney et al., 2015; Lee et al., 2015; Jaramillo et al., 2016; Jaramillo et al., 2017). This may help support the functional importance of Shank3 during early development. 
After observing no behavioral phenotypes in the adult knockout mice that resembled phenotypes in the germline deficient mice, we optimized the system to deplete Shank3 expression earlier in development. We observed similarly efficiency when working with this earlier time period, but it was still insufficient to reliably produce any phenotypes associated with germline deficiency. This suggests that there may be roles for Shank3 in development prior to the peak in synapse formation and elimination that is occurring during the time period chosen. We chose this period because the peak expression for most Shank3 isoforms is at P15 in mice (Wang et al., 2014). However, in humans, neurological phenotypes and hypotonia can be observed in newborns (Ha et al., 2017) and abnormal USVs can also be observed in Shank3 mutant mice as early as P4 (Wang et al., 2016). Moreover, that we observed different electrophysiological phenotypes in the EPKO condition compared to the AKO condition suggests that some roles of Shank3 in neuronal signaling may be developmentally regulate, but again, the variability in efficiency limits our ability to draw a definitive conclusion.

Relatively few studies have attempted to examine the inducibility or reversibility of ASD-like behaviors in mice through conditional knockout or genetic rescue (Guy et al., 2007; McGraw et al., 2011; Robinson et al., 2012; Lang et al., 2014; Rabaneda et al., 2014; Silva-Santos et al., 2015; Mei et al., 2016; Gu et al., 2019; Sonzogni et al., 2019). Among these studies, not all specifically examined repetitive behaviors or social communication deficits, the core symptoms of ASD. However, in general, these studies have indicated that certain phenotypes can be induced or reversed by manipulating gene expression, while other phenotypes are unchangeable (reviewed in (Hulbert and Jiang, 2017)). In particular, one study demonstrated that elevated self-grooming could be rescued (i.e. reduced to wildtype levels) by restoring Shank3 expression in mice that developed carrying a Shank3 mutation that disrupted most isoforms (Mei et al., 2016). Another recent study showed that an array of behavioral phenotypes could be prevented by rescuing Shank3 expression embryonically (Jaramillo et al., 2020). Taken together with the current study, these results suggest that Shank3 may be required for certain developmental processes, such as synapse formation, that can be triggered later by restoring its expression, but are not lost by disrupting Shank3 expression after development has already occurred.

\section{Limitations}

Previous studies utilizing the same system we attempted to use in the current study reported much more success regarding the efficiency of the gene deletion or restoration. We attempted to delete a relatively large portion of DNA, spanning 18 exons and $\sim 60 \mathrm{~kb}$ genomic DNA, which may have contributed to our limited efficiency. Previous studies also do not mention many adverse effects of tamoxifen, but mortality was a major problem in the current study across multiple routes of administration. In designing future experiments, researchers should be aware of the limitations that exist in using inducible knockout technology and should keep in mind that tamoxifen treatment may have some off-target effects (Semprini et al., 2007; Patel et al., 2017).

\section{Conclusions}


Our findings add to the growing concern regarding the interpretation of studies utilizing conditional knockout technology to study the plasticity of behavioral phenotypes associated with ASD. Another recent study reported apparent rescue of behavioral phenotypes in vehicle-treated CAGGs-CreER expressing Shank3 mutants, implicating some baseline behavioral effects produced by the Cre transgene (Speed et al., 2019). An alternative potential reason for the negative results presented in the current study is our inclusion of the appropriate Cre-positive mice that did not receive tamoxifen in our control groups, whereas previous studies did not implement all necessary controls. Although the conclusions we can draw about the developmental pathophysiology of ASD are not definitive due to technical constraints, our study does once again confirm that mice with germline deficiency of Shank3 have robust, repeatable phenotypes.

\section{Declarations}

\section{Ethics approval and consent to participate:}

All experiments were conducted with protocols approved by the Institutional Animal Care and Use Committee at Duke University.

\section{Consent for publication:}

Not applicable

\section{Availability of data and materials:}

All data generated or analyzed during this study are included in this published article.

\section{Competing interests:}

The authors declare no competing interests.

\section{Funding:}

Autism Speaks: Weatherstone Predoctoral Fellowship number 9597, National Institutes of Health: R01MH098114, R21HD087795; R21MH104316; R01MH117289

\section{Author Contributions:}

SWH designed research, performed research, analyzed data, and wrote the paper; HY performed research and analyzed data; XW, ALB, and MSL performed research, YJ designed research and wrote the paper 


\section{Acknowledgements:}

We would like to thank William Wetsel and Ramona Rodriguiz for technical support.

\section{References}

Bey AL, Wang X, Yan H, Kim N, Passman RL, Yang Y, Cao X, Towers AJ, Hulbert SW, Duffney LJ, Gaidis E, Rodriguiz RM, Wetsel WC, Yin HH, Jiang YH (2018) Brain region-specific disruption of Shank3 in mice reveals a dissociation for cortical and striatal circuits in autism-related behaviors. Translational psychiatry 8:94.

Boccuto L, Lauri M, Sarasua SM, Skinner CD, Buccella D, Dwivedi A, Orteschi D, Collins JS, Zollino M, Visconti P, Dupont B, Tiziano D, Schroer RJ, Neri G, Stevenson RE, Gurrieri F, Schwartz CE (2013) Prevalence of SHANK3 variants in patients with different subtypes of autism spectrum disorders. Eur $\mathrm{J}$ Hum Genet 21:310-316.

Bozdagi O, Sakurai T, Papapetrou D, Wang X, Dickstein DL, Takahashi N, Kajiwara Y, Yang M, Katz AM, Scattoni ML, Harris MJ, Saxena R, Silverman JL, Crawley JN, Zhou Q, Hof PR, Buxbaum JD (2010) Haploinsufficiency of the autism-associated Shank3 gene leads to deficits in synaptic function, social interaction, and social communication. Mol Autism 1:15.

Drapeau E, Dorr NP, Elder GA, Buxbaum JD (2014) Absence of strong strain effects in behavioral analyses of Shank3-deficient mice. Dis Model Mech 7:667-681.

Drapeau E, Riad M, Kajiwara Y, Buxbaum JD (2018) Behavioral Phenotyping of an Improved Mouse Model of Phelan-McDermid Syndrome with a Complete Deletion of the Shank3 Gene. eNeuro 5.

Duffney LJ, Wei J, Cheng J, Liu W, Smith KR, Kittler JT, Yan Z (2013) Shank3 deficiency induces NMDA receptor hypofunction via an actin-dependent mechanism. J Neurosci 33:15767-15778.

Duffney LJ, Zhong P, Wei J, Matas E, Cheng J, Qin L, Ma K, Dietz DM, Kajiwara Y, Buxbaum JD, Yan Z (2015) Autism-like Deficits in Shank3-Deficient Mice Are Rescued by Targeting Actin Regulators. Cell reports 11:1400-1413.

Durand CM et al. (2007) Mutations in the gene encoding the synaptic scaffolding protein SHANK3 are associated with autism spectrum disorders. Nat Genet 39:25-27.

Gu B, Carstens KE, Judson MC, Dalton KA, Rougie M, Clark EP, Dudek SM, Philpot BD (2019) Ube3a reinstatement mitigates epileptogenesis in Angelman syndrome model mice. J Clin Invest 129:163-168.

Guy J, Gan J, Selfridge J, Cobb S, Bird A (2007) Reversal of neurological defects in a mouse model of Rett syndrome. Science 315:1143-1147. 
Ha JF, Ahmad A, Lesperance MM (2017) Clinical characterization of novel chromosome 22q13 microdeletions. Int J Pediatr Otorhinolaryngol 95:121-126.

Hulbert SW, Jiang YH (2016) Monogenic mouse models of autism spectrum disorders: Common mechanisms and missing links. Neuroscience 321:3-23.

Hulbert SW, Jiang YH (2017) Cellular and Circuitry Bases of Autism: Lessons Learned from the Temporospatial Manipulation of Autism Genes in the Brain. Neuroscience bulletin 33:205-218.

Hulbert SW, Bey AL, Jiang YH (2018) Environmental enrichment has minimal effects on behavior in the Shank3 complete knockout model of autism spectrum disorder. Brain and behavior 8:e01107.

Jaramillo TC, Speed HE, Xuan Z, Reimers JM, Liu S, Powell CM (2016) Altered Striatal Synaptic Function and Abnormal Behaviour in Shank3 Exon4-9 Deletion Mouse Model of Autism. Autism Res 9:350-375.

Jaramillo TC, Xuan Z, Reimers JM, Escamilla CO, Liu S, Powell CM (2020) Early restoration of Shank3 expression in Shank3 knockout mice prevents core ASD-like behavioural phenotypes. eNeuro.

Jaramillo TC, Speed HE, Xuan Z, Reimers JM, Escamilla CO, Weaver TP, Liu S, Filonova I, Powell CM (2017) Novel Shank3 mutant exhibits behaviors with face validity for autism and altered striatal and hippocampal function. Autism Res 10:42-65.

Kouser M, Speed HE, Dewey CM, Reimers JM, Widman AJ, Gupta N, Liu S, Jaramillo TC, Bangash M, Xiao B, Worley PF, Powell CM (2013) Loss of predominant Shank3 isoforms results in hippocampus-dependent impairments in behavior and synaptic transmission. J Neurosci 33:18448-18468.

Lang M, Wither RG, Colic S, Wu C, Monnier PP, Bardakjian BL, Zhang L, Eubanks JH (2014) Rescue of behavioral and EEG deficits in male and female Mecp2-deficient mice by delayed Mecp2 gene reactivation. Hum Mol Genet 23:303-318.

Lee J, Chung C, Ha S, Lee D, Kim DY, Kim H, Kim E (2015) Shank3-mutant mice lacking exon 9 show altered excitation/inhibition balance, enhanced rearing, and spatial memory deficit. Front Cell Neurosci 9:94.

McGraw CM, Samaco RC, Zoghbi HY (2011) Adult neural function requires MeCP2. Science 333:186.

Mei Y, Monteiro P, Zhou Y, Kim JA, Gao X, Fu Z, Feng G (2016) Adult restoration of Shank3 expression rescues selective autistic-like phenotypes. Nature 530:481-484.

Moessner R, Marshall CR, Sutcliffe JS, Skaug J, Pinto D, Vincent J, Zwaigenbaum L, Fernandez B, Roberts W, Szatmari P, Scherer SW (2007) Contribution of SHANK3 mutations to autism spectrum disorder. Am J Hum Genet 81:1289-1297. 
Patel SH, O'Hara L, Atanassova N, Smith SE, Curley MK, Rebourcet D, Darbey AL, Gannon AL, Sharpe RM, Smith LB (2017) Low-dose tamoxifen treatment in juvenile males has long-term adverse effects on the reproductive system: implications for inducible transgenics. Scientific reports 7:8991.

Peça J, Feliciano C, Ting JT, Wang W, Wells MF, Venkatraman TN, Lascola CD, Fu Z, Feng G (2011) Shank3 mutant mice display autistic-like behaviours and striatal dysfunction. Nature 472:437-442.

Rabaneda LG, Robles-Lanuza E, Nieto-Gonzalez JL, Scholl FG (2014) Neurexin dysfunction in adult neurons results in autistic-like behavior in mice. Cell reports 8:338-346.

Robinson L, Guy J, McKay L, Brockett E, Spike RC, Selfridge J, De Sousa D, Merusi C, Riedel G, Bird A, Cobb SR (2012) Morphological and functional reversal of phenotypes in a mouse model of Rett syndrome. Brain: a journal of neurology 135:2699-2710.

Roussignol G, Ango F, Romorini S, Tu JC, Sala C, Worley PF, Bockaert J, Fagni L (2005) Shank expression is sufficient to induce functional dendritic spine synapses in aspiny neurons. J Neurosci 25:3560-3570.

Schmeisser MJ et al. (2012) Autistic-like behaviours and hyperactivity in mice lacking ProSAP1/Shank2. Nature 486:256-260.

Semprini S, Troup TJ, Kotelevtseva N, King K, Davis JR, Mullins LJ, Chapman KE, Dunbar DR, Mullins JJ (2007) Cryptic loxP sites in mammalian genomes: genome-wide distribution and relevance for the efficiency of BAC/PAC recombineering techniques. Nucleic Acids Res 35:1402-1410.

Silva-Santos S, van Woerden GM, Bruinsma CF, Mientjes E, Jolfaei MA, Distel B, Kushner SA, Elgersma Y (2015) Ube3a reinstatement identifies distinct developmental windows in a murine Angelman syndrome model. J Clin Invest 125:2069-2076.

Sonzogni M, Hakonen J, Bernabe Kleijn M, Silva-Santos S, Judson MC, Philpot BD, van Woerden GM, Elgersma Y (2019) Delayed loss of UBE3A reduces the expression of Angelman syndrome-associated phenotypes. Mol Autism 10:23.

Soorya L, Kolevzon A, Zweifach J, Lim T, Dobry Y, Schwartz L, Frank Y, Wang AT, Cai G, Parkhomenko E, Halpern D, Grodberg D, Angarita B, Willner JP, Yang A, Canitano R, Chaplin W, Betancur C, Buxbaum JD (2013) Prospective investigation of autism and genotype-phenotype correlations in 22q13 deletion syndrome and SHANK3 deficiency. Mol Autism 4:18.

Speed HE, Kouser M, Xuan Z, Liu S, Duong A, Powell CM (2019) Apparent Genetic Rescue of Adult Shank3 Exon 21 Insertion Mutation Mice Tempered by Appropriate Control Experiments. eNeuro.

Speed HE, Kouser M, Xuan Z, Reimers JM, Ochoa CF, Gupta N, Liu S, Powell CM (2015) Autism-Associated Insertion Mutation (InsG) of Shank3 Exon 21 Causes Impaired Synaptic Transmission and Behavioral Deficits. J Neurosci 35:9648-9665. 
Wang X, Xu Q, Bey AL, Lee Y, Jiang YH (2014) Transcriptional and functional complexity of Shank3 provides a molecular framework to understand the phenotypic heterogeneity of SHANK3 causing autism and Shank3 mutant mice. Mol Autism 5:30.

Wang X, McCoy PA, Rodriguiz RM, Pan Y, Je HS, Roberts AC, Kim CJ, Berrios J, Colvin JS, Bousquet-Moore D, Lorenzo I, Wu G, Weinberg RJ, Ehlers MD, Philpot BD, Beaudet AL, Wetsel WC, Jiang YH (2011) Synaptic dysfunction and abnormal behaviors in mice lacking major isoforms of Shank3. Hum Mol Genet 20:3093-3108.

Wang X et al. (2016) Altered mGluR5-Homer scaffolds and corticostriatal connectivity in a Shank3 complete knockout model of autism. Nature communications 7:11459.

Zhou Y, Kaiser T, Monteiro P, Zhang X, Van der Goes MS, Wang D, Barak B, Zeng M, Li C, Lu C, Wells M, Amaya A, Nguyen S, Lewis M, Sanjana N, Zhang M, Zhang F, Fu Z, Feng G (2016) Mice with Shank3 Mutations Associated with ASD and Schizophrenia Display Both Shared and Distinct Defects. Neuron 89:147-162.

\section{Figures}

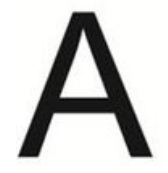

Shank3

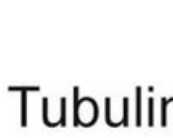

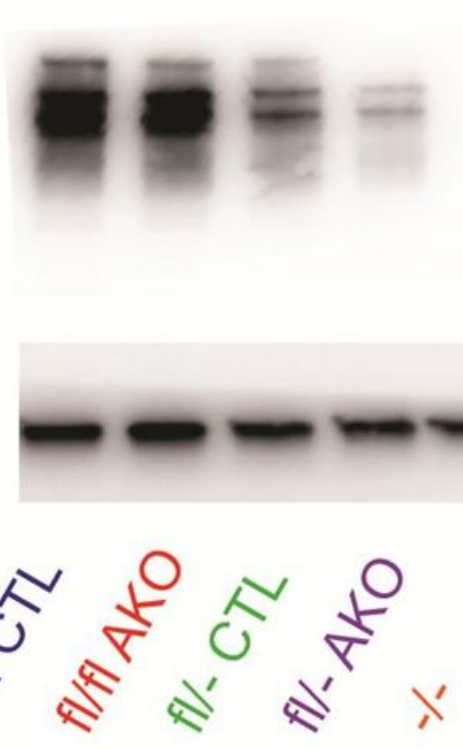
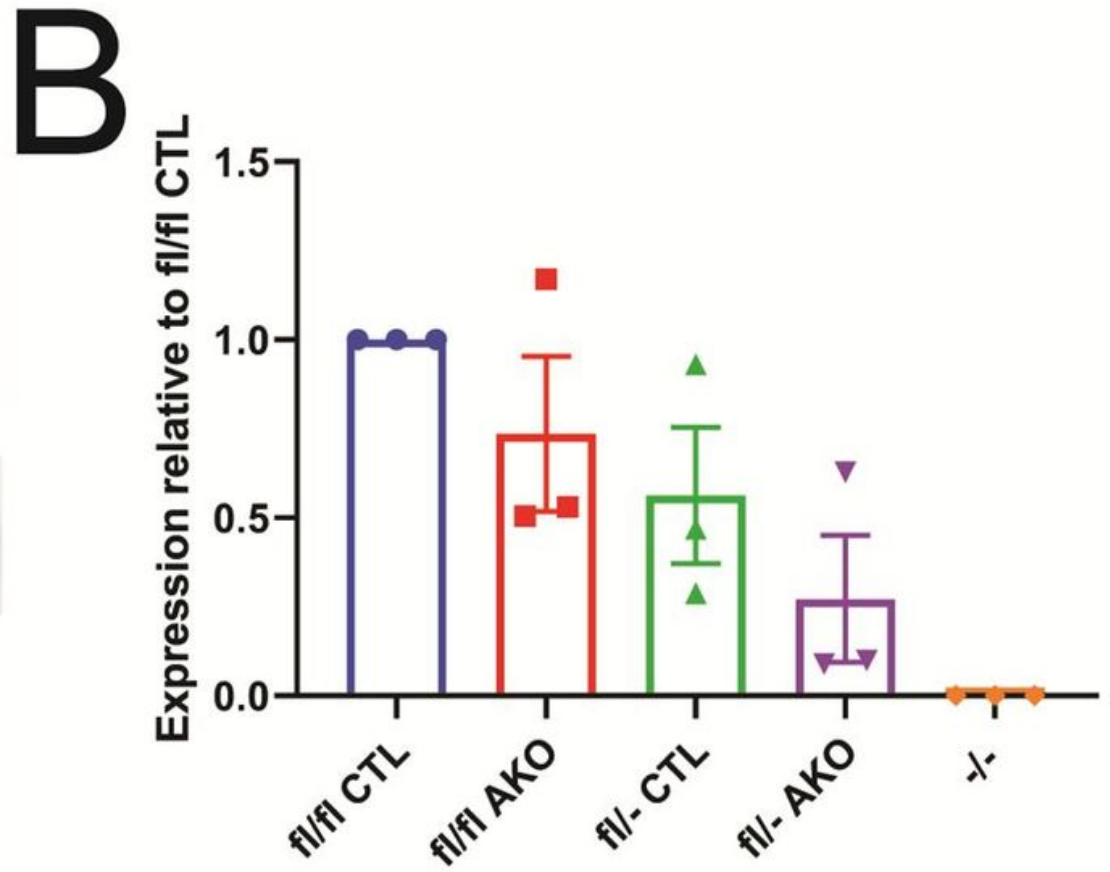

\section{Figure 1}

Shank3 protein expression can be depleted in adult mice incompletely using conditional knockout techniques. (A) Representative western blot of PSD fractions from striata in mice in each of the five groups (fl/fl CTL, $\mathrm{fl} / \mathrm{fl} A K O, f l /-C T L, f l /-A K O,-/-)$ showing Shank3 expression levels. $\boldsymbol{\beta}$-tubulin was used as 
a loading control. (B) Quantification of Shank3 expression normalized to $\mathrm{fl} / \mathrm{fl}$ control levels $(\mathrm{n}=3$ mice per group).
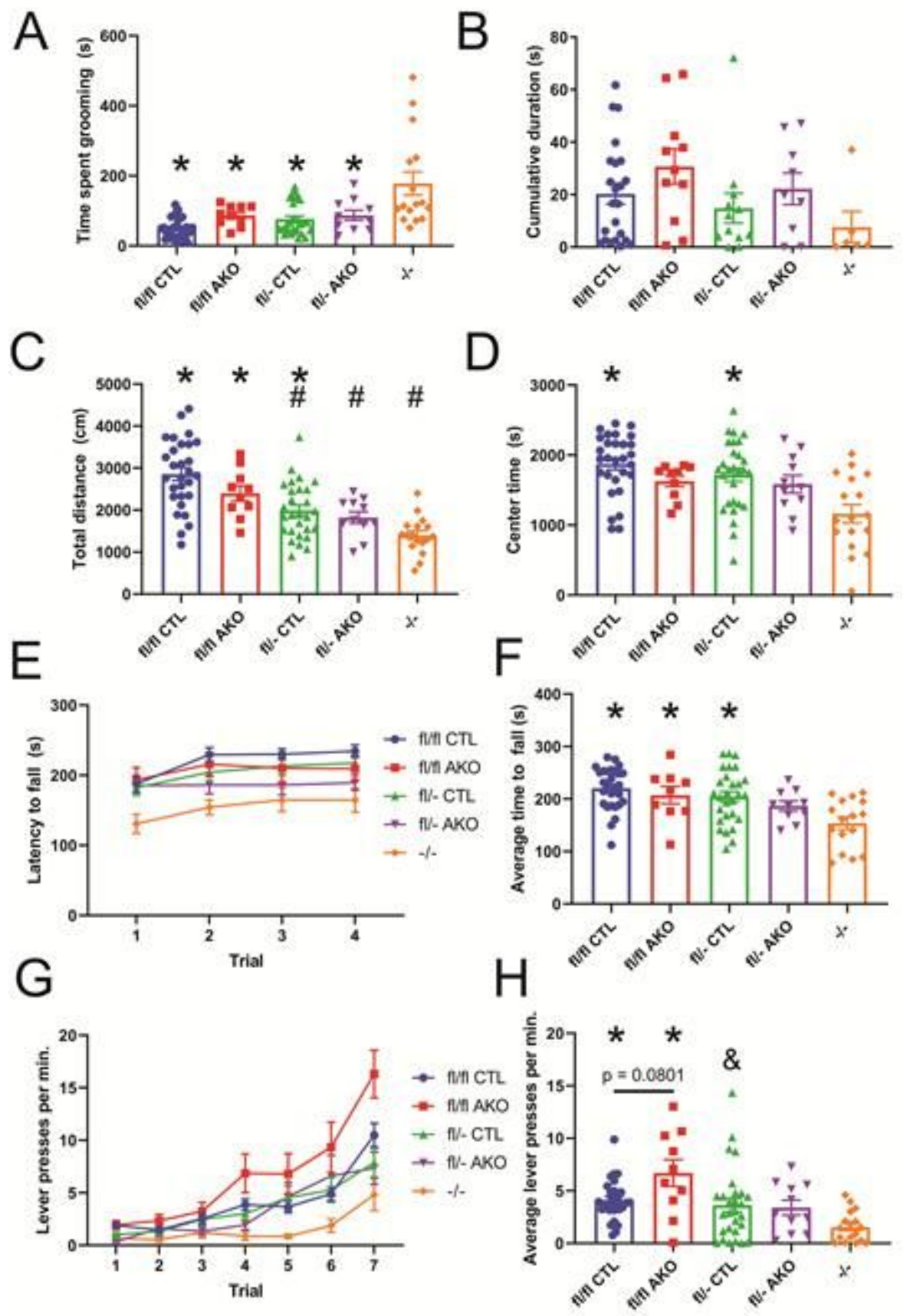

Figure 2

Disrupting Shank3 expression in adult mice does not produce phenotypes associated with germline deficiency. (A) Germline Shank3e4-22-/- mice spent significantly more time self-grooming than any other group (one-way ANOVA $p<0.0001$; Tukey's multiple comparisons $-/-v s$. fl/fl CTL $p<0.0001,-/-v s$. fl/fl AKO $p=0.0061,-/-$ vs. fl/- CTL $p<0.0001,-/-v s$. fl/- AKO $p=0.0064)$. There were no significant differences between any other groups. (B) There were no significant differences between groups in cumulative duration of ultrasonic vocalizations (one-way ANOVA $p=0.1549$ ). (C) There were differences between groups in distance traveled in the open field (one-way ANOVA $p<0.0001$ ) but no significant 
differences between conditional knockout groups and their control groups by Tukey's multiple comparisons post-hoc test. Shank3e4-22-/- mice were significantly hypoactive compared to $\mathrm{fl} / \mathrm{fl} \mathrm{CTL}, \mathrm{fl} / \mathrm{fl}$ AKO, and fl/- CTL groups ( $<<0.0001, p=0.0023$, and 0.0333, respectively) and fl/fl CTL mice traveled significantly more distance than fl/- CTL, fl/- AKO, and Shank3e4-22-/- mice $(\mathrm{p}<0.0001, \mathrm{p}=0.0002$, and $\mathrm{p}$ $<0.0001$, respectively). There were no significant differences between any other groups. (D) Shank3e4$22-/$ - mice spent less time in the center of the arena (one-way ANOVA $p<0.0001$ ) compared to $\mathrm{fl} / \mathrm{fl} \mathrm{CTL}$ mice (Tukey's multiple comparisons, $p<0.0001$ ) and fl/- CTL mice (Tukey's multiple comparisons, $p=$ 0.0016). There were no significant differences between any other groups. (E) On the accelerating rotarod, there was a main effect of group on latency to fall (RMANOVA, $p=0.0003$ ). (F) Tukey's multiple comparisons on the rotarod data revealed significant differences between Shank3e4-22/- mice and fl/fl CTL mice $(p<0.0001)$, fl/fl AKO mice $(p=0.0434)$, and fl/- CTL mice $(p=0.0051)$. There were no significant differences between any other groups. (G) On the operant conditioning task, there was a main effect of group on performance (RMANOVA, $p=0.0003)$. $(H)$ Tukey's multiple comparisons on the operant data revealed significant differences between Shank3e4-22-/- mice and two groups: fl/fl CTL mice $(p=$ $0.0203)$ and $\mathrm{fl} / \mathrm{fl}$ AKO mice $(\mathrm{p}<0.0001)$. The $\mathrm{fl} / \mathrm{fl}$ AKO mice also pressed significantly more than $\mathrm{fl} / \mathrm{C} \mathrm{CTL}$ mice $(p=0.0239)$ and tended to press more than $f / f l C T L$ mice, but this difference was not quite significant $(p=0.0801)$. There were no significant differences between any other groups. *represents a significant difference $(p<0.05)$ between $-/$ - mice and the experimental group below. \#represents a significant difference $(p<0.05)$ between $\mathrm{fl} / \mathrm{fl}$ CTL mice and the experimental group below. \&represents a significant difference $(p<0.05)$ between $\mathrm{fl} / \mathrm{fl}$ AKO mice and the experimental group below. 

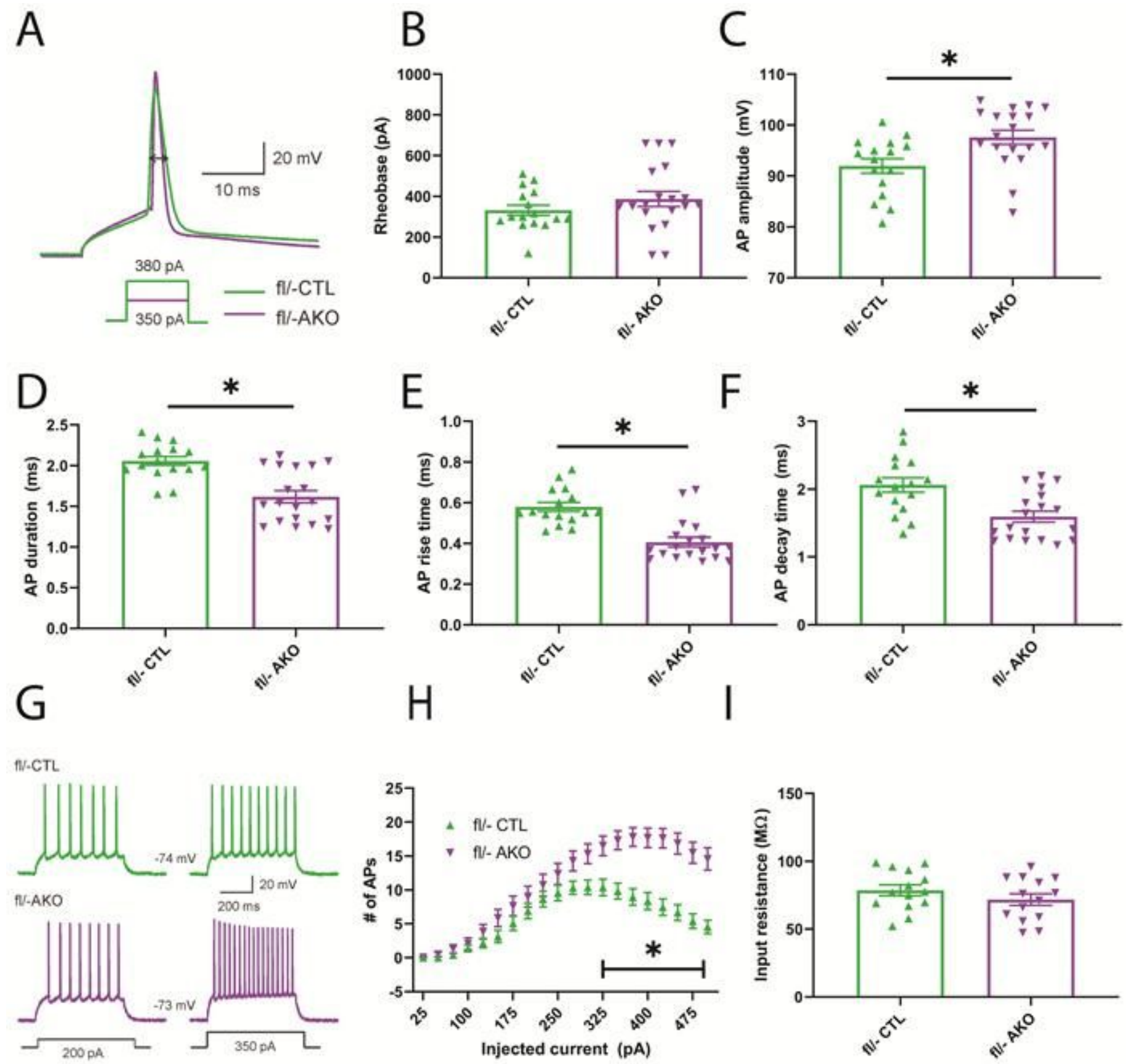

Figure 3

Disrupting Shank3 expression in adult mice changes firing properties of medium spiny neurons in the striatum. (A) Representative overlaid traces of a single action potential evoked by a $10 \mathrm{~ms}$ current injection (current amplitude shown in parentheses) in striatal medium spiny neurons (MSNs) from fl/CTL mice and fl/- AKO mice. (B) Current threshold to induce an action potential (Rheobase) is not significantly altered in slices from fl/- AKO mice (unpaired t-test, $\mathrm{p}=0.2467)$. (C) Action potential amplitude was significantly increased in recordings from fl/- AKO mice compared to fl/- CTL mice (unpaired t-test, $\mathrm{p}=0.0074$ ). (D) The duration of action potentials was significantly decreased in fl/- AKO mice compared to fl/- CTL mice (unpaired t-test, $p<0.0001$ ). (E) The rise time was significantly decreased in $\mathrm{fl} /$ - AKO mice compared to $\mathrm{fl} /$ - CTL mice (unpaired t-test, $\mathrm{p}<0.0001)$. (F) The decay time was 
significantly decreased in fl/- AKO mice compared to fl/- CTL mice (unpaired t-test, $\mathrm{p}=0.0011)$. $(\mathrm{G})$ Representative traces of evoked action potentials at two different current injection amplitudes (shown in insets) in MSNs from fl/- CTL mice (top) and fl/- AKO mice (bottom). The resting membrane potential is indicated. $(\mathrm{H})$ The number of evoked action potentials for the indicated amplitude of current injection. There are significantly more action potentials fired in fl/- AKO mice compared to fl/- CTL mice when the injected current was $325 \mathrm{pA}$ and above (two-way ANOVA, $\mathrm{p}<0.0001$; Holm-Sidak multiple comparisons: $\mathrm{fl} /-\mathrm{CTL}$ vs. fl/- $\mathrm{AKO}$ at $325 \mathrm{pA}, \mathrm{p}=0.0074$, at $350 \mathrm{pA}, \mathrm{p}=0.0003$, at 375-500 pA, $\mathrm{p}<0.0001$ ). (I) There was no significant difference (unpaired t-test, $p=0.2496$ ) in input resistance between $\mathrm{fl} / \mathrm{CTL}$ and $\mathrm{fl} / \mathrm{-AKO}$ mice. *represents a significant difference $(\mathrm{p}<0.05)$ between $\mathrm{fl} /$ - CTL mice and fl/- AKO mice.

\section{A}

Shank3

\section{Tubulin}

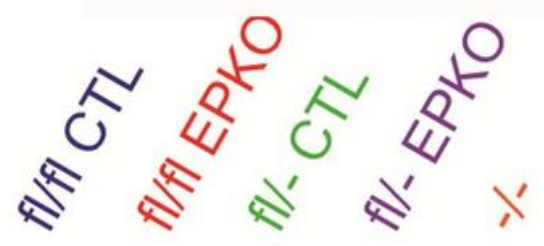

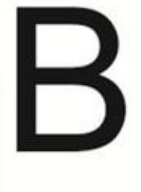

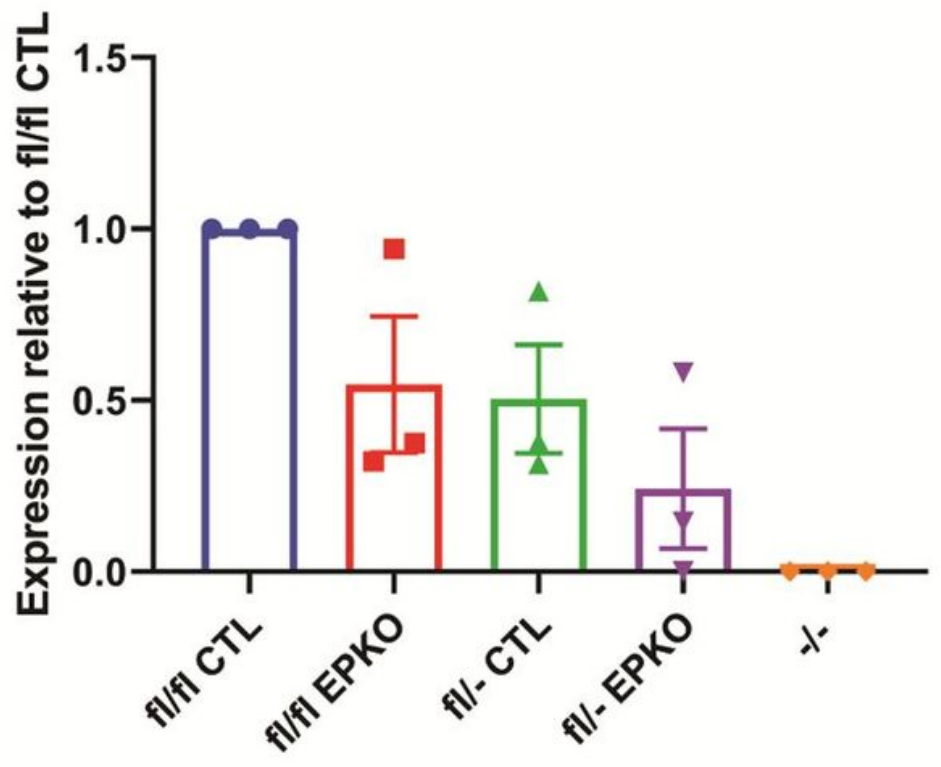

\section{Figure 4}

Shank3 protein expression can be depleted in developing mice incompletely using conditional knockout techniques. (A) Representative western blot of PSD fractions from striata in mice in each of the five groups (fl/fl CTL, fl/fl EPKO, fl/- CTL, fl/- EPKO, -/-) showing Shank3 expression levels. $\boldsymbol{\beta}$-tubulin was used as a loading control. (B) Quantification of Shank3 expression normalized to $\mathrm{fl} / \mathrm{fl}$ control levels $(\mathrm{n}=3$ mice per group). 


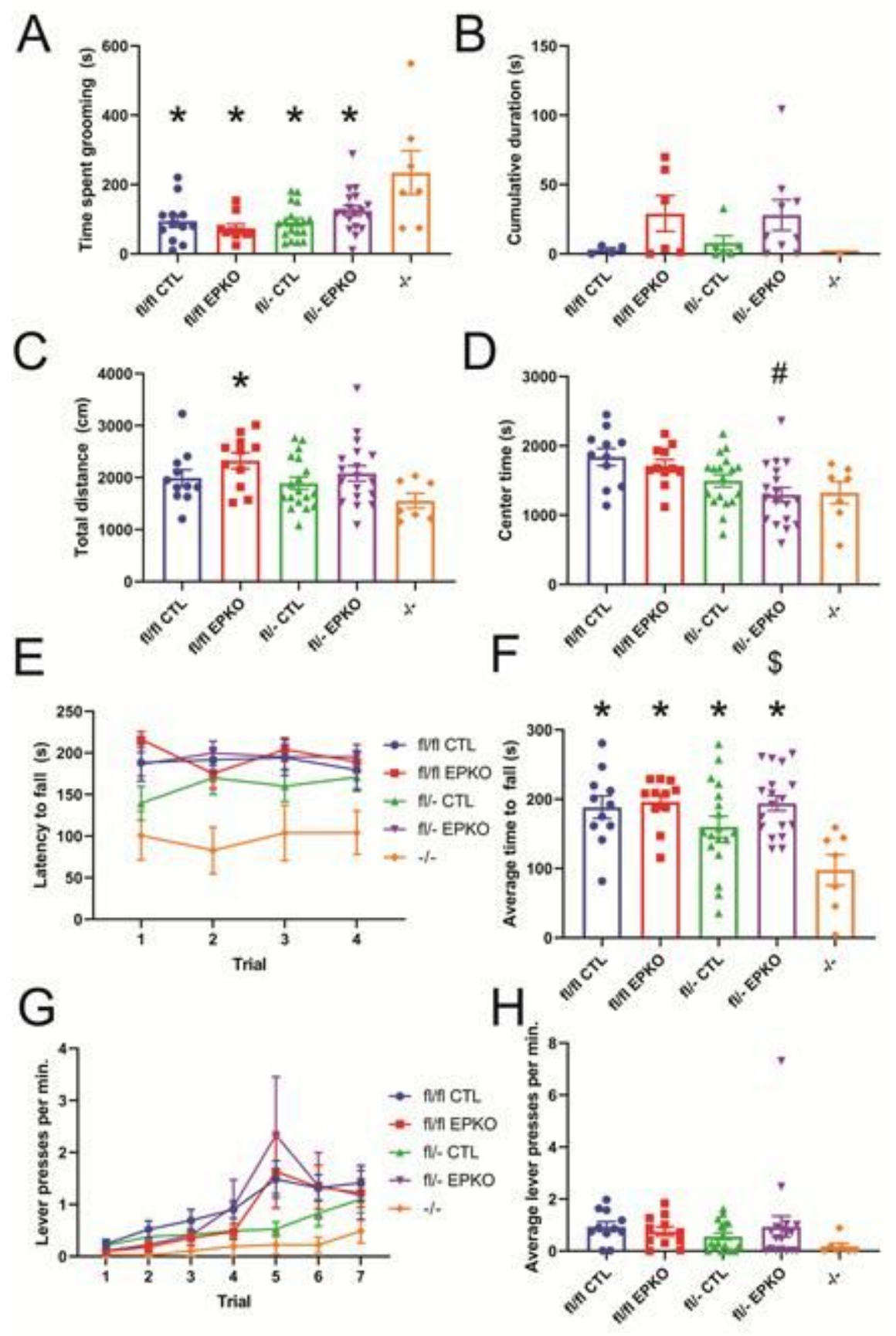

Figure 5

Early postnatal disruption of Shank3 expression does not produce phenotypes associated with germline deficiency. (A) Germline Shank3e4-22-/- mice spent significantly more time self-grooming than any other group (one-way ANOVA $p=0.0003$; Tukey's multiple comparisons $-/-v s$. fl/fl CTL $p=0.0017,-/-v s$. fl/fl EPKO $p=0.0004,-/-$ vs. fl/- CTL $p=0.0005,-/-$ vs. fl/- EPKO $p=0.0117)$. There were no significant differences between any other groups. (B) There were no significant differences between groups in cumulative duration of ultrasonic vocalizations (one-way ANOVA $p=0.3231$ ). (C) There was a main effect of experimental group on distance traveled in the open field (one-way ANOVA $p=0.0491$ ) but no significant differences between conditional knockout groups and their control groups by Tukey's multiple comparisons post-hoc test. The only significant difference after post-hoc analysis was between 
Shank3e4-22-/- mice and fl/fl EPKO mice $(p=0.0317)$. (D) There was a main effect of experimental group on time spent in the center of the open field (one-way ANOVA $p=0.0036$ ) but no significant differences between conditional knockout groups and their control groups by Tukey's multiple comparisons post-hoc test. The only significant difference after post-hoc analysis was between fl/fl CTL mice and fl/- EPKO mice $(p=0.0054)$. (E) On the accelerating rotarod, there was a main effect of group on latency to fall (RMANOVA, $p=0.0011)$. (F) Tukey's multiple comparisons on the rotarod data revealed Shank3e4-22-/mice performed significantly worse than all other groups: $f l / f l$ CTL mice $(p<0.0001)$, fl/fl EPKO mice $(p<$ $0.0001)$, fl/- CTL mice $(p=0.0006)$, and fl/- EPKO mice $(p<0.0001)$. In addition, fl/- EPKO mice performed significantly better than $\mathrm{fl} / \mathrm{CTL}$ mice $(\mathrm{p}=0.0246)$. $(\mathrm{G}-\mathrm{H})$ On the operant conditioning task, there was no effect of experimental group on performance (RMANOVA, $p=0.4893$ ), nor was there an interaction effect (RMANOVA, $p=0.9059)$. *represents a significant difference $(p<0.05)$ between $-/$ - mice and the experimental group below. \#represents a significant difference $(p<0.05)$ between $f l / f l C T L$ mice and the experimental group below. Srepresents a significant difference $(p<0.05)$ between $f l /-C T L$ mice and the experimental group below. 
A
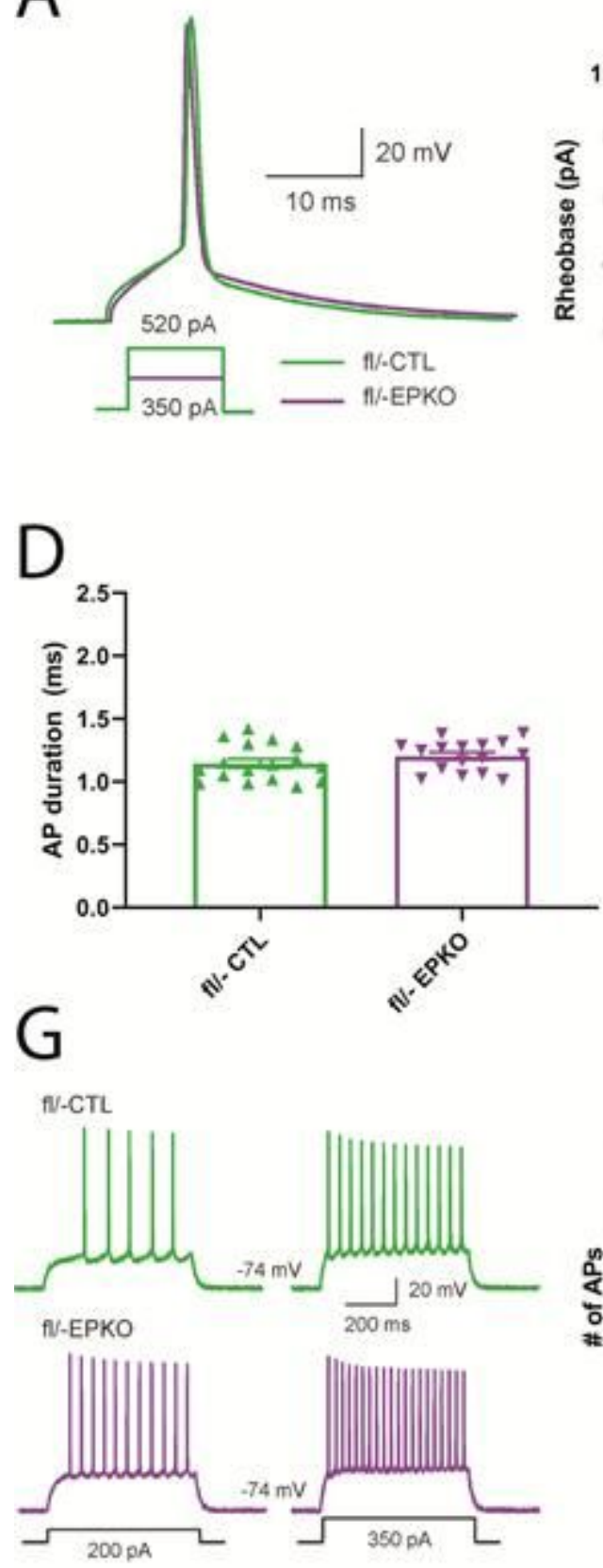
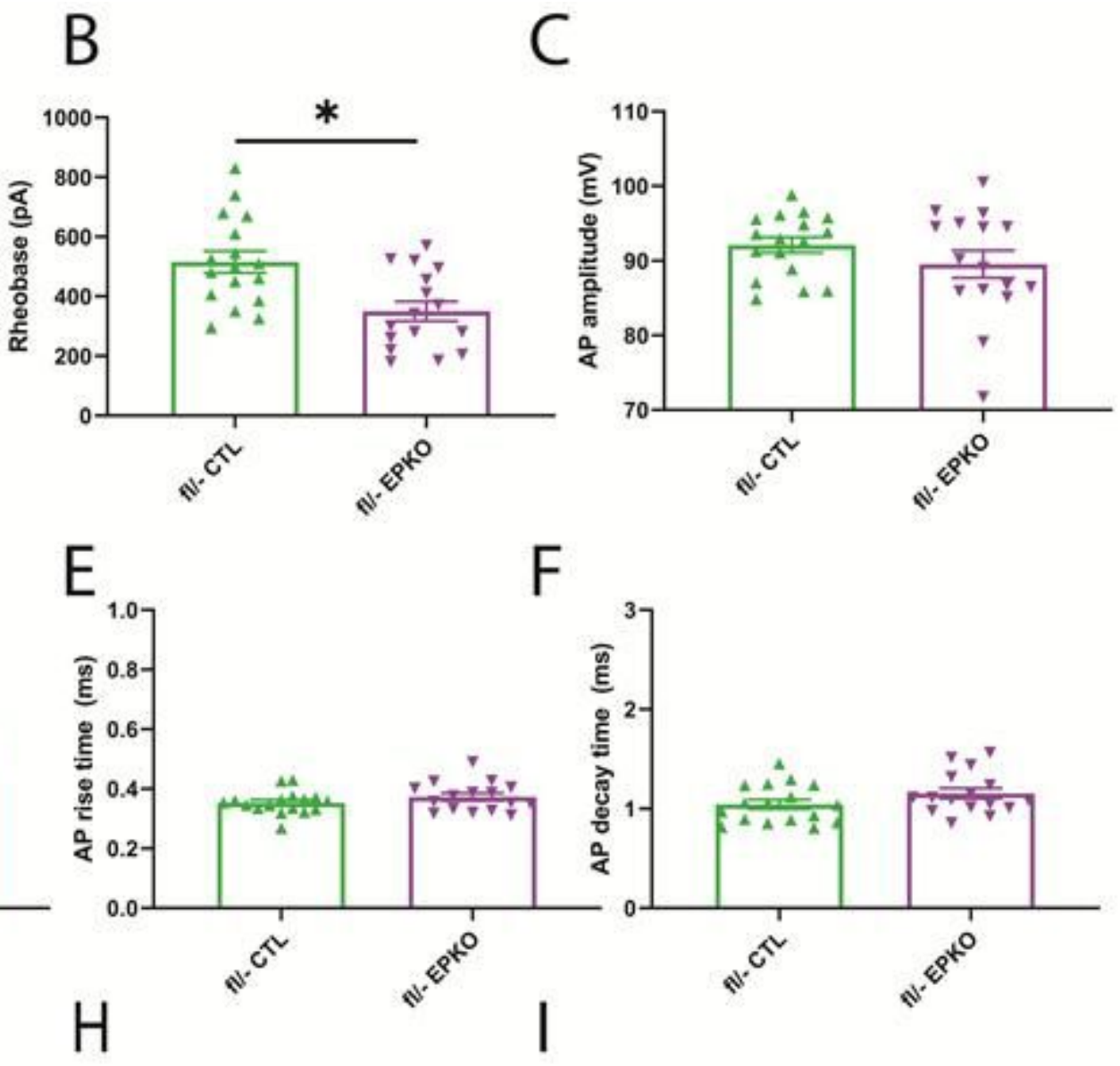

$\mathrm{F}$
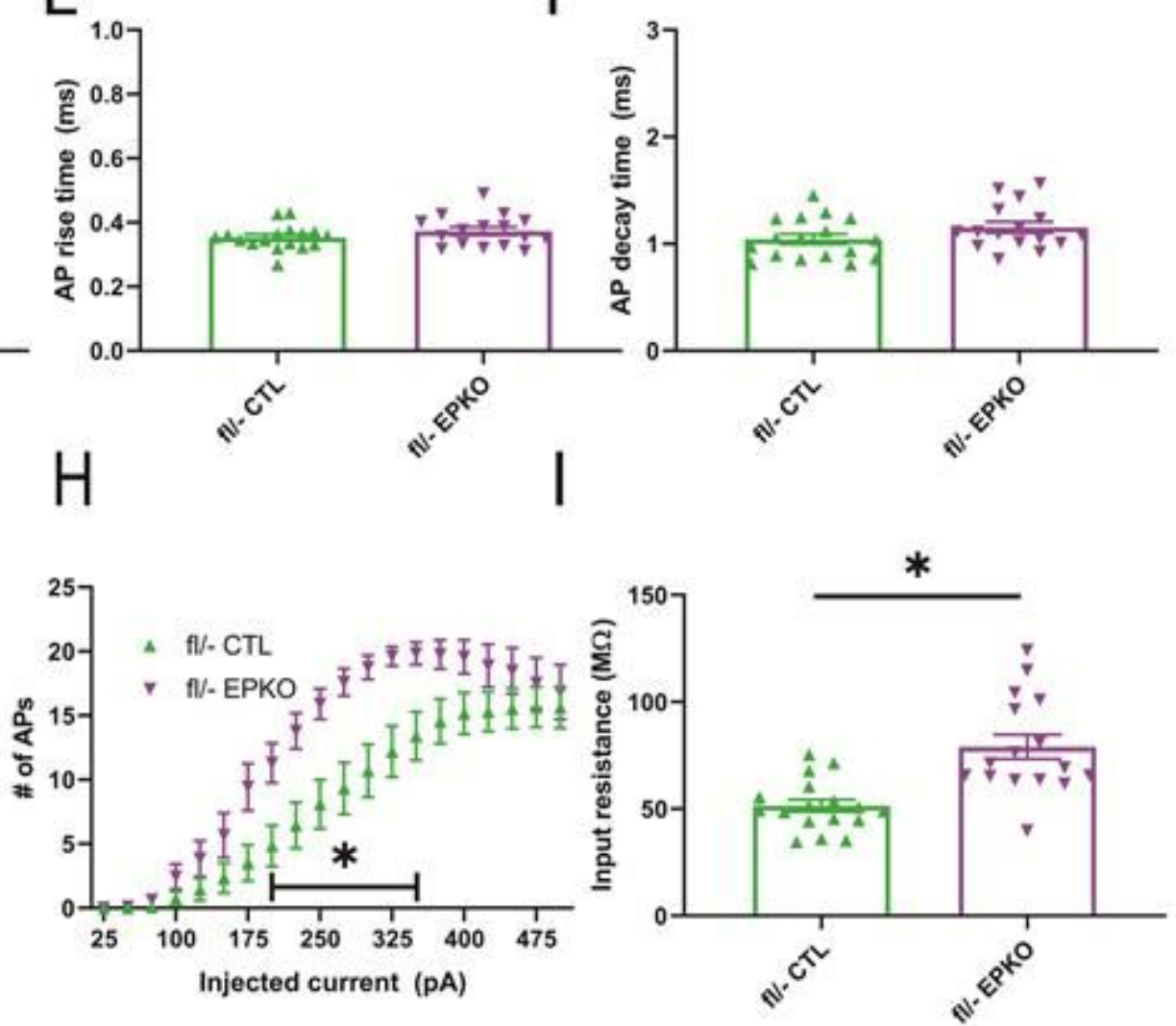

Figure 6

Early postnatal disruption of Shank3 expression alters electrophysiology in the striatum. (A) Representative overlaid traces of single action potentials evoked with a $10 \mathrm{~ms}$ current injection (amplitude shown in parentheses) in striatal MSNs from fl/- CTL mice and fl/- EPKO mice. (B) Current threshold to induce an action potential (Rheobase) is significantly lower in fl/- EPKO mice compared to their controls (unpaired t-test, $p=0.0021$ ). (C) Action potential amplitude was not significantly different between recordings from fl/- EPKO mice and those from fl/- CTL mice (unpaired t-test, $p=0.2272$ ). (D) The duration of action potentials was not significantly changed in fl/- EPKO mice compared to fl/- CTL mice (unpaired t-test, $p=0.2173$ ). ( $E$ ) The rise time was not significantly different between $\mathrm{fl} /$ - EPKO mice and fl/- CTL mice (unpaired t-test, $p=0.2040)$. $(F)$ The decay time was not significantly different in fl/- 
EPKO mice compared to fl/- CTL mice (unpaired t-test, $p=0.1300$ ). (G) Representative traces of evoked action potentials for the indicated experimental groups at two separate current injection amplitudes (shown in insets). The resting membrane potential is indicated. $(H)$ The number of evoked action potentials for the indicated amplitude of current injection. There are significantly more action potentials fired in fl/- EPKO mice compared to fl/- CTL mice when the injected current was 200-350 pA (two-way ANOVA, $p<0.0001$; Holm-Sidak multiple comparisons: fl/- CTL vs. fl/- EPKO at $200 \mathrm{pA} \mathrm{p}=0.0310$, at 225 $p A p=0.0062$, at $250 p A p=0.0026$, at $275 p A p=0.0010$, at $300 p A p=0.0016$, at $325 p A p=0.0056$, at $350 \mathrm{pA} \mathrm{p}=0.0313$ ). (I) Recordings from fl/- EPKO mice had significantly increased input resistance compared to fl/- CTL mice (unpaired t-test, $p<0.0001$ ). 